\title{
Inexperience and risky decisions of young adolescents, as pedestrians and cyclists, in interactions with lorries, and the effects of competency versus awareness education
}

Citation for published version (APA):

Twisk, D., Vlakveld, W., Mesken, J., Shope, J. T., \& Kok, G. (2013). Inexperience and risky decisions of young adolescents, as pedestrians and cyclists, in interactions with lorries, and the effects of competency versus awareness education. Accident Analysis and Prevention, 55, 219-225.

https://doi.org/10.1016/j.aap.2013.02.038

Document status and date:

Published: 01/06/2013

DOI:

10.1016/j.aap.2013.02.038

Document Version:

Publisher's PDF, also known as Version of record

Please check the document version of this publication:

- A submitted manuscript is the version of the article upon submission and before peer-review. There can be important differences between the submitted version and the official published version of record. People interested in the research are advised to contact the author for the final version of the publication, or visit the DOI to the publisher's website.

- The final author version and the galley proof are versions of the publication after peer review.

- The final published version features the final layout of the paper including the volume, issue and page numbers.

Link to publication

\footnotetext{
General rights rights.

- You may freely distribute the URL identifying the publication in the public portal. please follow below link for the End User Agreement:

www.umlib.nl/taverne-license

Take down policy

If you believe that this document breaches copyright please contact us at:

repository@maastrichtuniversity.nl

providing details and we will investigate your claim.
}

Copyright and moral rights for the publications made accessible in the public portal are retained by the authors and/or other copyright owners and it is a condition of accessing publications that users recognise and abide by the legal requirements associated with these

- Users may download and print one copy of any publication from the public portal for the purpose of private study or research.

- You may not further distribute the material or use it for any profit-making activity or commercial gain

If the publication is distributed under the terms of Article 25fa of the Dutch Copyright Act, indicated by the "Taverne" license above, 


\section{Inexperience and risky decisions of} young adolescents, as pedestrians and cyclists, in interactions with lorries, and the effects of competency versus awareness education

Divera Twisk', Willem Vlakveld ${ }^{1}$, Jolieke Mesken ${ }^{1}$, Jean T. Schope ${ }^{2}{ }^{3}$, Gerjo Kok $^{4}$

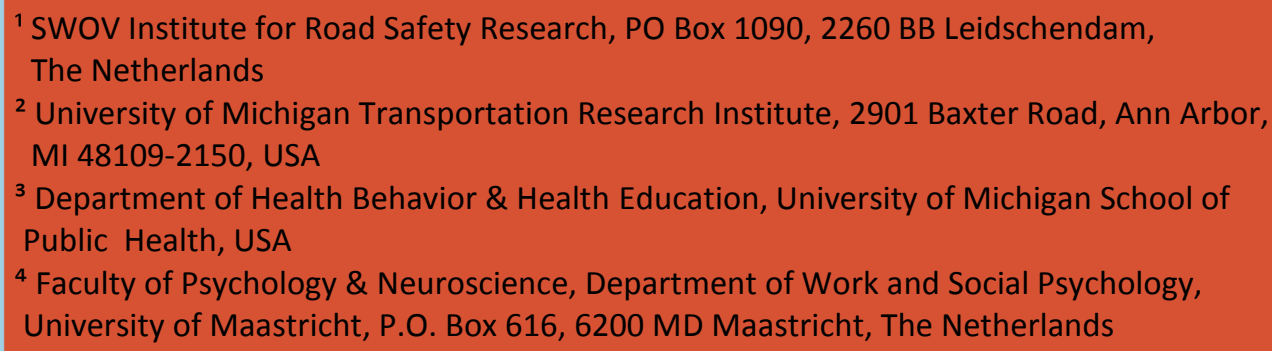




\title{
Inexperience and risky decisions of young adolescents, as pedestrians and cyclists, in interactions with lorries, and the effects of competency versus awareness education
}

\author{
Divera Twisk', Willem Vlakveld ${ }^{1}$, Jolieke Mesken', Jean T. Schope ${ }^{2}{ }^{3}$, Gerjo Kok $^{4}$ \\ ${ }^{1}$ SWOV Institute for Road Safety Research, PO Box 1090, 2260 BB Leidschendam, The Netherlands \\ 2 University of Michigan Transportation Research Institute, 2901 Baxter Road, Ann Arbor, MI 48109-2150, USA \\ ${ }^{3}$ Department of Health Behavior \& Health Education, University of Michigan School of Public Health, USA \\ ${ }^{4}$ Faculty of Psychology \& Neuroscience, Department of Work and Social Psychology, University of Maastricht, \\ P.O. Box 616, 6200 MD Maastricht, The Netherlands
}

Road injuries are a prime cause of death in early adolescence. Often road safety education (RSE) is used to target risky road behaviour in this age group. These RSE programmes are frequently based on the assumption that deliberate risk taking rather than lack of competency underlies risk behaviour. This study tested the competency of 10-13 year olds, by examining their decisions - as pedestrians and cyclists - in dealing with blind spot areas around lorries. Also, the effects of an awareness programme and a competency programme on these decisions were evaluated.

Table-top models were used, representing seven scenarios that differed in complexity: one basic scenario to test the identification of blind spot areas, and 6 traffic scenarios to test behaviour in traffic situations of low or high task complexity. Using a quasi-experimental design (pre-test and posttest reference group design without randomization), the programme effects were assessed by requiring participants $(n=62)$ to show, for each table-top traffic scenario, how they would act if they were in that traffic situation.

On the basic scenario, at pre-test $42 \%$ of the youngsters identified all blind spots correctly, but only $27 \%$ showed safe behaviour in simple scenarios and $5 \%$ in complex scenarios. The competency programme yielded improved performance on the basic scenario but not on the traffic scenarios, whereas the awareness programme did not result in any improvements. The correlation between improvements on the basic scenarios and the traffic scenarios was not significant.

Young adolescents have not yet mastered the necessary skills for safe performance in simple and complex traffic situations, thus underlining the need for effective prevention programmes. RSE may improve the understanding of blind spot areas but this does not 'automatically' transfer to performance in traffic situations. Implications for the design of RSE are discussed.

\section{Introduction}

Road safety education (RSE) programmes are widely used with the goal of changing behaviour among young adolescents, so that injuries and fatalities are prevented. However, little is known regarding whether these programmes address the relevant determinants of risk behaviour, achieve their objectives, and actually change behaviour (Dragutinovic and Twisk, 2006; SUPREME, 2007; Williams, 2007). For example, blind spot programmes have become increasingly popular to educate and train 
young cyclists and pedestrians, now that the additional mirrors on lorries - compulsory in the EU since 2003 - and other technical systems that seek to improve lorry drivers' view, have only led to a temporary reduction in fatalities (Schoon et al., 2008). Of all fatal crashes between cyclists and lorries in the period 1997 and 2006, 45\% happen because of cyclists being in the driver's blind spot. Of those blind spot fatal crashes, $28 \%$ involves a cyclist in the age category 0-17 (Schoon et al., 2008). To date little is known about the antecedents of these risky decisions. Is it that youngsters hold safety compromising attitudes and beliefs, resulting in 'carelessness' and deliberate ignoring of these risks? Or is it that these youngsters lack the necessary skills to deal with these potential risks, and just do not know what to do? Whereas education programmes for children are implicitly based on the assumption that they are still inexperienced road users, those for young adolescents tend to focus on attitudes and beliefs as the main determinants of risky behaviour (Dragutinovic and Twisk, 2006). The latter focus is supported by results from epidemiologic studies showing a strong rise in all sorts of risky behaviours in this age group, such as smoking, alcohol use, and petty crime (Dorsselaer et al., 2007; Ezinga et al., 2008; Junger et al., 2003; Kumpula and Paavola, 2008), and by results from studies on the psychological determinants suggesting that youngsters are well aware of risks (e.g., Reyna and Farley, 2006; Steinberg, 2008) but still behave in a risky manner because of strong desires for novel and exciting experiences, high desire for peer approval, and low impulse control (Dahl, 2004). In contrast, studies on expertise development, however, support the possible role of inexperience as a determinant of risk behaviour, pointing to the slow acquisition of new skills (Anderson, 1982) and the necessity of deliberate practice (Ericsson, 2005). Also, several behaviour models point to the importance of expertise, in that skills are a restricting factor for attitudes/beliefs to influence road behaviour (e.g., Fuller, 2008). That is, despite a positive safety motivation youngsters may still behave risky because of poor skills. Although this distinction between 'attitudes/beliefs' and 'inexperience' is of utmost importance for the design of RSE programmes (Bartholomew et al., 2006), until now this information has not been available. Therefore, the present study examined the initial proficiency of 10-13 year old adolescents in simple and complex blind spot situations, and evaluated and compared the effects of two types of blind spot education programmes: a programme aimed at raising proficiency and a programme aimed at increasing risk awareness. The study focussed on blind spot situations because of the complex psychological mechanisms involved, the high incidence of this type of situation in road traffic, and the serious consequences of such a crash.

With respect to the competency of young adolescents - before the intervention - the following hypotheses were formulated. Because blind spot scenarios require the recognition of situations in which lorry drivers can easily make errors, and the processing of information that may contain contradictory cues and distractors (Endsley, 1995; Fuller, 2008), road users need to possess abilities such as 'empathy', 'perspective-taking', and 'selective and focussed attention'. These abilities, however, are not yet fully developed in early adolescence, partly because of the immaturity of the adolescent brain (Blakemore and Choudhury, 2006; Keating, 2007). It is therefore expected that youngsters will frequently make risky decisions in blind spot situations (H1). The development of these skills may be accelerated by practice on the task (Crone and Dahl, 2012; Johnson et al., 2010; Keating, 2007), whereby the simple tasks require less practice than the more complex ones (Anderson, 1982; Ericsson, 2005; Shriffrin and Schneider, 1977). Young adolescents in the Netherlands have had little practical experience with these blind spot situations. It is therefore 
expected that risky decisions will be made more frequently in complex traffic situations containing contradictory cues and distractors than in simple ones $(\mathrm{H} 2)$.

In the evaluation study, two blind spot programmes were assessed. The awareness programme addressed carelessness, not only in blind spot scenarios, but also in other traffic situations. The competency programme solely addressed blind spot hazards and used a condensed message of only four rules: (a) do not cross the street right in front or right behind a lorry; (b) at signalized intersections, always wait behind the stop line; (c) when approaching an intersection, stay behind the lorry; and (d) make sure the lorry driver sees you. Besides these differences, the programmes were very similar. Both were comprised of a half-day of instruction, whereby a real lorry was placed in the schoolyard. The limitations in the lorry driver's field of view were demonstrated and information on safe behaviour was provided. Participants could climb into the driver's seat and see for themselves where the blind spots were located. Blind spots were further illustrated through graphic representations and videos. Practical training in real-world situations was not included in either of the programmes. Both programmes visited schools on request, the costs were often covered by subsidies from local governments, and instructors were volunteers, frequently retired lorry drivers.

This study further tested the validity of the presumed didactic mechanisms. Both programmes implicitly assumed a successful 'far' transfer of learning (Barnett and Ceci, 2002), meaning that the mere provision of instruction and demonstration were expected to yield better performance in actual traffic situations. The present study hypothesized that if demonstrations of blind spots and instructions were sufficient for improving actual behaviour in traffic, improvements in the 'identification of blind zones' should be associated with improved performance in simple and complex traffic scenarios (H3).

The evaluation was conducted in a field setting in schools that already used the programmes on a regular basis. Performance was assessed by means of table-top models representing traffic situations. The field setting was chosen because of the study's aim to inform policy makers, teachers and educators about the 'net' effect of the programmes in use. The table-top model was used for two reasons: first, because exposing adolescents to real traffic situations would be too dangerous and second, because the evaluation study required rigorous control over task complexity.

Even though these RSE programmes were intended to improve road safety and thus reduce injury rates, the evaluation study only used 'road decisions' as a success criterion. Because crashes are rare, an evaluation study aiming to demonstrate effects on crashes and fatalities, would have required sample sizes of thousands of participants and extremely long observation periods (Hauer, 2008). Still, based on the assumptions that competency is a precondition for safe decisions and safe decisions reduce crash risk, this study uses 'change in the number of safe decisions' as an indicator of the potential impact these programmes may have on road safety.

\section{Methods}

\section{Participants}

Four primary schools in the Netherlands participated in the study: two intervention and two reference schools. The intervention schools were those that came first in the programme's 'tour scheme'. These schools were matched in terms of geographical location with two reference schools 
that used neither of the programmes. No other criteria were used for matching. All participants $(n=$ 63) of the last two grades of these four primary schools participated in the study and completed both the pre- and the post-test as part of their regular school day. They were between 10 and 13 years of age. In the intervention group, $49 \%$ of the participants were boys. In the reference group, this proportion was $51 \%$.

\section{Design}

A quasi-experimental approach with a non-equivalent control group design (Cook and Campbell, 1979) and a split plot factorial (SPF) design (Jones, 2009) was employed. Identical task scenarios were used for pre- and post-test. The pre-test was administered just before the programme and the posttest about 1 month later.

\section{Task scenarios}

Seven table-top models of traffic scenarios were employed to assess performance. These table-top models were approximately 1 by $2 \mathrm{~m}$ in size, each depicting a schematic road layout in 2D and containing scaled movable models in 3D of cars, lorries, pedestrians, and cyclists. Participants were instructed that the pedestrians and cyclist models represented 'themselves' and were asked to indicate on the table-top model where they would wait or where they would cross in that given traffic situation. These tasks did not require a correct assessment of speed or distance. Three complexity levels were used:

- One basic scenario. Using a scaled model of a lorry, participants were required to indicate locations at which the lorry driver would or would not be able to see them.

- Three simple traffic scenarios. In these scenarios no distractors were present and safe behaviour only required the application of a single 'rule'.

- Three complex traffic scenarios. These scenarios were complex because of additional features that complicated the decision process, such as the presence of distractors, extra information, or conflicting rules.

Figure 1 shows examples of the scenarios with two levels of complexity. The order in which scenarios were presented was the same for all participants, and did not differ between pre- and post-test. The first, third, and fourth scenarios were simple while the second, fifth, and seventh scenarios were complex. The sixth scenario was the basic scenario. 

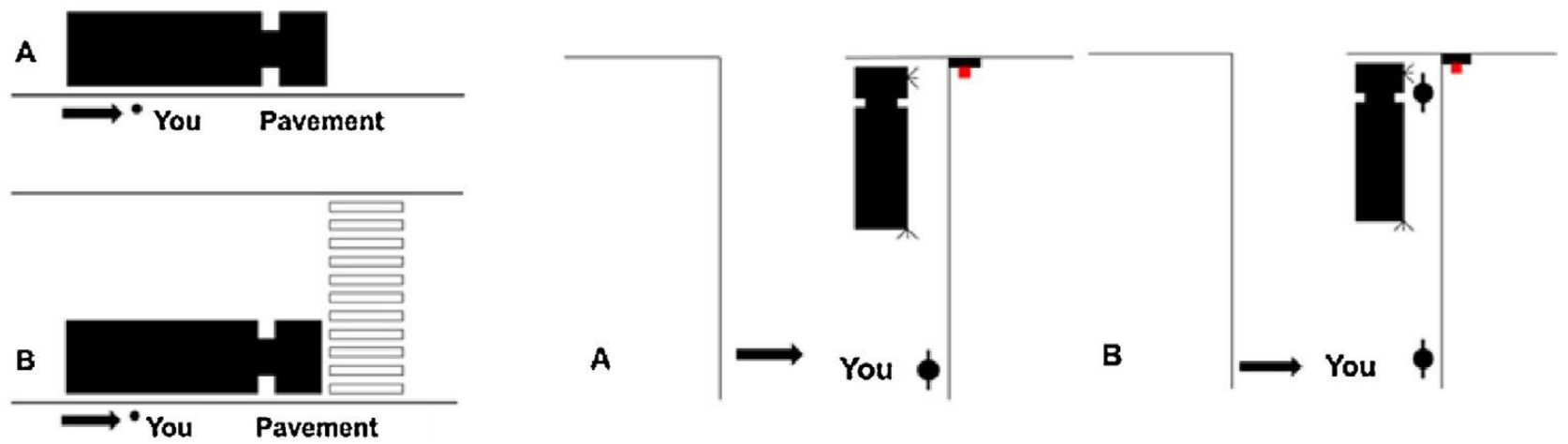

Figure 1: Schematic examples of simple (A) and complex (B) scenarios. The scenario on the right invites participants to apply the rule, "On approaching an intersection with a lorry waiting at a red light, always wait behind the lorry". The arrow highlights the position of the model representing the participant. In the B condition, complexity is added by positioning another cyclist in the blind spot, as distractor. The scenario on the left represents a lorry parked at the curb with the engine running. It invites participants to apply the rule, "Do not cross a street right in front of a lorry". The B condition adds complexity by showing a pedestrian crossing.

\section{Procedure}

At the intervention schools, the programme was carried out as usual, with the exception that participants, instructors and school staff were informed about the purpose of the evaluation. The control schools did not receive an intervention. No information was collected on the actual delivery of the programmes, but feedback from the organizers of the programmes pointed out that there had been no abnormalities. To test performance, a research assistant met with each participant individually in a room in the participant's school, and described the main characteristics of each scenario. Participants were then instructed to demonstrate on the table-top by moving a model piece representing them, how they would act in that scenario as a cyclist or pedestrian. For example, the instruction for the intersection scenario shown in Fig. 1 read: "You approach this intersection on your bicycle. The traffic light is red. A lorry is waiting at the stop line and its turn signals show that it plans to turn right once the light is green. You want to go straight. Please position your bicycle where you would wait while the traffic light is red". If participants waited behind the lorry, they were awarded one point. If they positioned the bicycle between the lorry and the pavement, no point was awarded. No feedback was given on the correctness of the decision, and no incentive was provided.

\section{Measures}

The following measures were used in the analyses: (a) performance by complexity, calculated as the sum of scores on the scenarios within each complexity level; (b) gain scores, calculated as the difference between the performance on the pre- and post- test for each participant; (c) mastery, calculated as the proportion of participants that received the highest possible score within a complexity level. 


\section{Data analysis}

Initial competency levels were assessed using mixed design ANOVA with task complexity as a withinsubject variable and gender and grade as between-subject variables. The effects of the programmes were assessed using mixed design ANOVA with pre- test and post-test as within-subject variables and experimental group as a between-subject variable.

\section{Results}

\section{Initial (baseline) proficiency}

The total mean and mastery scores at baseline, shown in Table 1, indicate that about $67 \%$ of the participants correctly identified all blind spots, but only $43 \%$ made safe decisions in all simple scenarios and $3 \%$ in all complex scenarios. This finding supports the hypothesis that young adolescents frequently make risky decisions in blind spot situations (H1). Regarding the influence of task complexity on performance ( $\mathrm{H} 2)$, Table 1 shows that performance deteriorated with increasing task complexity, resulting in lower mean scores for the complex scenarios $(M=1.2)$ than for the simple scenarios $(M=2.2)$. Inspection showed that the data did not meet the 'normality' and 'homogeneity' assumptions. However, as discussed by Field (2009, p. 360), in studies such as these, where Group sizes are equal, the F-statistic can be quite robust to violations of normality and homogeneity. The mixed design ANOVA, with task complexity as the within-subject variable and gender and grade as between-subject variables, showed the main effect of complexity to be statistically significant $(F(1,57)=64.64 ; p<.001$, with a medium effect size partial $772=.53)$. No interactions were present for gender $(F(1,57)=1.74 ; p<.19)$ and grade $(F(1,57)=.34 ; p<.58)$. The correlation between the basic and complex traffic scenarios was weak and not significant $(r=15.2 ; p$ $<.23 ; \mathrm{n}=63$ ), which does not support $\mathrm{H} 3$ that expected a strong relationship between the correct identification of blind spots and safe behaviour in traffic scenarios. Mastery was affected by task complexity, with the highest proportion of participants with correct responses on simple traffic scenarios (43\%) and the lowest on the complex traffic scenarios (5\%). This finding provides support for $\mathrm{H} 2$ that expected task performance to deteriorate with task complexity, and that therefore, lack of competency is likely to be one of the determinants of risk behaviour.

Table 1: Performance at baseline by complexity $(N=63$, all schools both programmes)

\begin{tabular}{|l|l|l|l|l|}
\hline $\begin{array}{l}\text { Scenarios by } \\
\text { complexity }\end{array}$ & Min-max score & Mean at baseline & SD & $\begin{array}{l}\text { Mastery (all items } \\
\text { correct) }\end{array}$ \\
\hline Basic & $0-6$ & 5.4 & 1.9 & $42(67 \%)$ \\
\hline Simple & $0-3$ & 2.2 & .78 & $27(43 \%)$ \\
\hline Complex & $0-3$ & 1.2 & .78 & $3(5 \%)$ \\
\hline Total & $0-12$ & 8.9 & 1.9 & $0(0 \%)$ \\
\hline
\end{tabular}


Table 2: Pre- and post-test means by complexity level, education programme, and experimental group.

\begin{tabular}{|c|c|c|c|c|c|c|c|c|c|c|}
\hline \multicolumn{3}{|c|}{ Education programme } & \multicolumn{4}{|c|}{ Pre-test by complexity (maximum scores) } & \multicolumn{4}{|c|}{ Post-test by complexity (maximum scores) } \\
\hline & & & $\begin{array}{l}\text { Total } \\
\text { (12) }\end{array}$ & Basic (6) & $\begin{array}{l}\text { Simple } \\
\text { (3) }\end{array}$ & $\begin{array}{l}\text { Complex } \\
\text { (3) }\end{array}$ & $\begin{array}{l}\text { Total } \\
(12)\end{array}$ & Basic (6) & $\begin{array}{l}\text { Simple } \\
\text { (3) }\end{array}$ & $\begin{array}{l}\text { Complex } \\
\text { (3) }\end{array}$ \\
\hline \multirow{4}{*}{$\stackrel{\varrho}{\mathcal{O}}$} & $\begin{array}{l}\text { Intervention } \\
n=19\end{array}$ & M & 8.2 & 5.2 & 2.0 & 1.0 & 9.5 & 5.8 & 2.2 & 1.5 \\
\hline & & (SD) & (2.5) & (1.8) & (.9) & (.7) & (1.8) & (.7) & (.9) & (.9) \\
\hline & $\begin{array}{l}\text { Reference } \\
n=20\end{array}$ & M & 8.7 & 5.6 & 2.1 & 1.0 & 8.5 & 5.2 & 2.3 & 1.0 \\
\hline & & $(\mathrm{SD})$ & (1.4) & (.7) & (.8) & (.7) & (1.8) & (1.2) & $(.8)$ & (.8) \\
\hline \multirow{4}{*}{$\frac{0}{\frac{0}{\pi}}$} & $\begin{array}{l}\text { Intervention } \\
n=12\end{array}$ & M & 9.5 & 5.5 & 2.4 & 1.6 & 9.7 & 5.7 & 2.6 & 1.4 \\
\hline & & (SD) & (1.4) & $(.8)$ & (.7) & (.8) & (1.1) & (.5) & (.5) & (.5) \\
\hline & $\begin{array}{l}\text { Reference } \\
n=12\end{array}$ & M & 9.6 & 5.6 & 2.6 & 1.4 & 9.3 & 5.6 & 2.3 & 1.3 \\
\hline & & (SD) & (1.2) & (.5) & $(.5)$ & $(.8)$ & (1.5) & (.8) & $(.8)$ & (.7) \\
\hline
\end{tabular}

Comp: Competency programme

Aware: Awareness raising programme.

\section{Effects of the education programmes}

\section{Ceiling effects and non-equivalence of experimental groups}

Potential effects of the programmes could have been obscured by two phenomena: (a) a ceiling effect, where performance scores at pre-test would be close to the maximum score; and (b) nonequivalence of groups where scores of the reference and intervention group would differ at pre-test. In terms of the former, a comparison of the pre-test performance scores with the maximum attainable score showed that for the basic scenario, mean scores were close to maximum but still left some room for improvement, and that for simple and complex scenarios, mean scores were well below the maximum score (see Table 2). Programme effects were thus not impacted by ceiling effects. Regarding the equivalence of groups, analyses showed that for both programmes the intervention and reference groups did not differ at pre-test.

Between the programmes, however, scores of the intervention group differed at pre-test (see Table 2). A mixed design ANOVA with complexity as the within-subject factor and programme as the between-subject factor showed a significant main effect of programme $(F(1,61)=7.98, p=.04$; partial $772=.12)$, a main effect of complexity $(F(1,61)=95.89, p<.001 ;$ partial 772.61$)$, but no interactions between programme and complexity, indicating that compared to the competency programme, participants in the awareness programme performed better at pre-test on all three types of scenarios. Unfortunately, we did not gather background information on the schools and could therefore not clarify why the 'competency' schools had lower pre-test scores than the 'awareness' schools. The difference on the pre-test between the programmes was not considered problematic because the evaluation sought to compare the experimental groups within programmes 
rather than between programmes. Furthermore, the pre-test score for the better performing awareness programmes still left sufficient room for improvement in all three complexity conditions.

\section{Effects by complexity level}

For each programme separately, the effects of the task performance for the three complexity levels were assessed. To that end, the improvements relative to the reference group were tested by means of mixed ANOVAs, with 'time' - pre-test and post- test - within-subject and 'intervention' intervention group and reference group - as between-subject variables. The interactions between time and intervention conditions, summarized in Table 3, confirmed that the competency programme yielded significant improvements on the basic and the total scores $(p<.05)$, but not on the simple and complex scenarios. The awareness programme, however, did not yield significant improvements on any of the complexity levels.

\section{Transfer and mastery}

Because only the competency programme yielded significant improvements, detailed analyses of the degree to which improvements on the basic scenarios were transferred to traffic scenarios were only conducted for that programme. Kendall's tau on the gain scores did not result in significant correlations between improvements on the basic scenario and the combined scores on the simple and complex scenarios. Therefore, $\mathrm{H} 3$ stating that improvement on the basic scenarios is associated with performance improvement on traffic scenarios was not confirmed.

Mastery improved in the competency programme's intervention group for all complexity levels while only minor changes in mastery were found in the reference group (Fig. 2). Among participants in the intervention group, $90 \%$ received the maximum score on the basic scenario at post-test. Success rates fell rapidly on the traffic scenarios. On the simple scenarios, only $47 \%$ of the intervention group dealt appropriately with each scenario. For the complex scenarios, this percentage was a mere $11 \%$.

Table 3:Analysis of variance: interactions between intervention and time by scenario type.

\begin{tabular}{|lllllllll|}
\hline Scenarios & \multicolumn{1}{l}{ Competency programme } & \multicolumn{5}{c|}{ Awareness programme } \\
\hline & Df & $\mathrm{F}$ & $\eta^{2}{ }{ }_{p}$ & $\mathrm{P}$ & $\mathrm{Df}$ & $\mathrm{F}$ & $\eta^{2}{ }_{\mathrm{P}}$ & $\mathrm{P}$ \\
\hline Basic & $1 ; 37$ & 4.84 & .01 & .03 & $1 ; 22$ & .23 & .63 \\
Simple & $1 ; 37$ & .12 & & .73 & $1 ; 22$ & 1.15 & .30 \\
Complex & $1 ; 37$ & 2.82 & & .10 & $1 ; 22$ & .05 & .83 \\
Total & $1 ; 37$ & 7.93 & .12 & .03 & $1 ; 22$ & .04 & .84 \\
\hline
\end{tabular}

Note: Summary table of the interactions between time and intervention based on separate ANOVAs for each programme and complexity level with test (pre- and post-test scores) as the within-subject measure (time) and intervention group (reference versus intervention) as the grouping factor. 


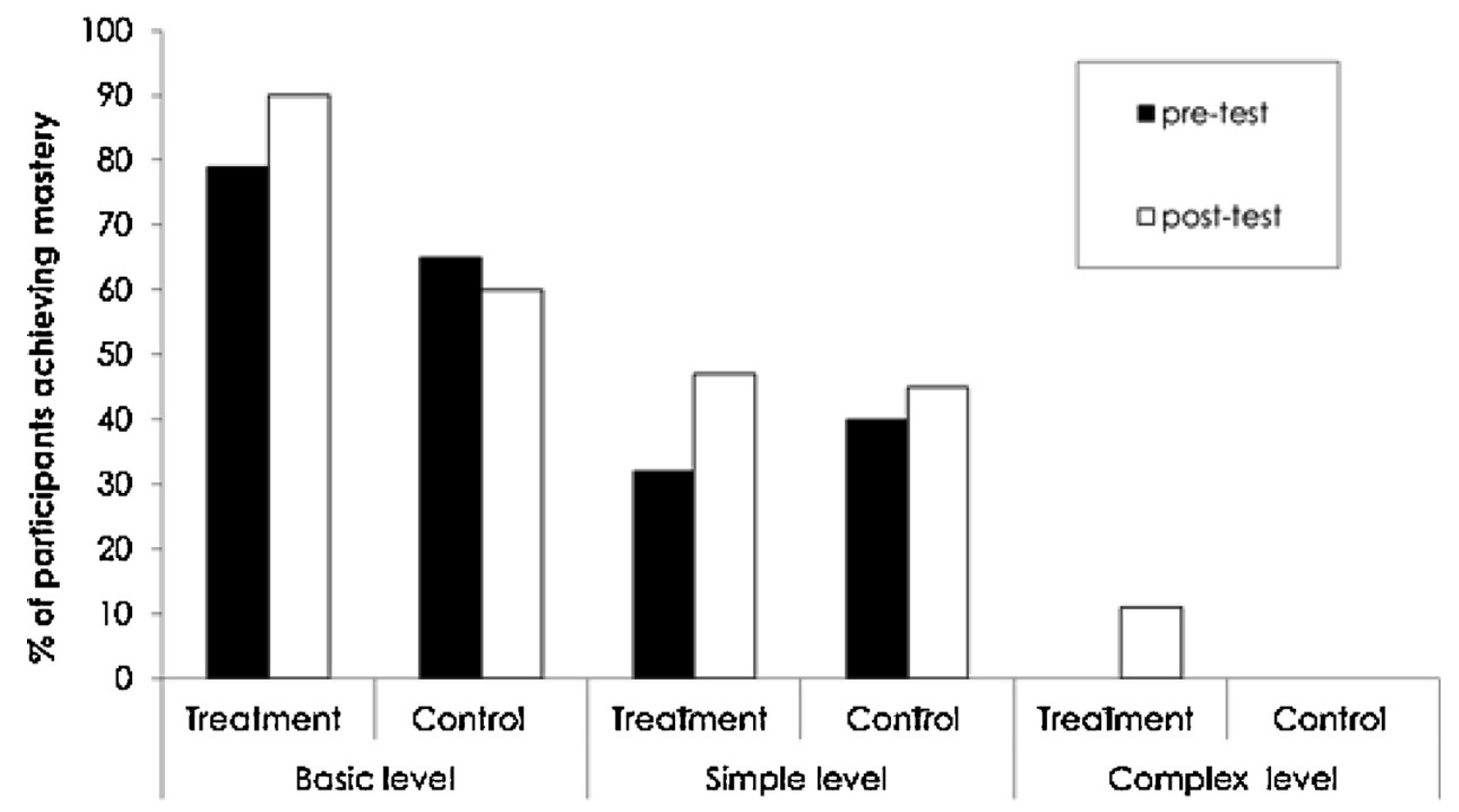

Figure 2: Proportion of participants exhibiting mastery (1 point on each scenario within a complexity level) at pre- and post-test for competency programme by scenario complexity and experimental group.

\section{Discussion}

\section{Summary of results}

The objectives of this study were to: (a) assess the initial performance of how young adolescents interact with lorries at varying levels of task complexity, (b) evaluate the effects of two road safety education (RSE) programmes on performance in traffic scenarios, and (c) assess the expected impact of the programmes on road safety. Because only the competency programme yielded improved performance, objective $c$ was only assessed for that programme.

The results from the study support the hypothesis that Young adolescents in blind spot situations make decisions that increase their risk of being overlooked by the driver. About a third of participants did not correctly identify all blind spot locations. Performance deteriorated further in traffic scenarios in which this knowledge needed to be applied - only one out of two participants made safe decisions in all simple scenarios and only one out of twenty did so in all complex scenarios. This difference by scenario complexity supports the hypothesis that lack of skills, rather than unsafe attitudes/beliefs, underlies these risky decisions.

The programmes' didactic assumptions that unsafe behaviour results from poor identification of blind spot locations and that unsafe behaviour can be improved by training on blind spot identification were not supported by the findings, as the correct identification of blind spots did not predict the safety of their decisions in the traffic scenarios, and improved on the blind spot identification after the competency programme did not lead to improved behaviour in traffic scenarios. Based on the assumption that correct performance on the traffic scenarios is a 
precondition for safe behaviour in actual traffic situations, it is unlikely that the competency programme will have a positive impact on road safety.

\section{Strength and weaknesses of the study}

Three characteristics of the study may have affected the generalisability of the results for road safety: (a) the use of table-top models, (b) the absence of an experimental condition in which the factor 'deliberate risk taking' was manipulated, and (c) the field setting.

The table-top models enabled the manipulation of scenario complexity, eliminated interference from other sources, provided participants with sufficient time to complete the task, and prevented exposure to hazardous conditions. Despite these advantages, one could debate the degree to which these table-top models were adequate representations of real traffic situations. Although the external validity of the method could not be assessed for safety reasons, the finding that complex scenarios yielded a higher number of incorrect responses than simple scenarios indicates that the experimental conditions of task complexity were adequately manipulated. The greatest threat to external validity, however, is the absence of dynamic features and time pressure that is characteristic to modern traffic. Most likely, this absence has led to an overestimation of the competency of young adolescents in actual traffic, which implies that the poor performances on the table top may serve merely as an indicator of an even greater problem.

The experimental manipulation in this study was adequate for the assessment of proficiency, but less suitable for assessing the influence of safety-compromising attitudes - doing so would have called for a separate manipulation of motivation and drives, such as the introduction of peer pressure (Gardner and Steinberg, 2005), frustration, or immediate rewards for risk behaviours (Reyna and Rivers, 2008). Based on the present study, it cannot be ruled out that in addition to lack of competency, deliberate risk-taking may also play a role in risky behaviour in blind spot situations.

The field setting did not allow the random assignment of schools to conditions. Moreover, only 4 schools participated in the study. These facts weaken the conclusions of the evaluation study regarding the magnitude of the effects, and limit the generalisability of the results. However, the results on the initial levels of competency - before the intervention - do not suffer from these limitations, and are still indicative of the high frequency of risky decisions made by this age group, that very likely result from poor skills.

\section{Implications for road safety education}

If anything, the present study has pointed out the role of lack of competency in adolescent risk behaviour and the inadequacy of current programmes to enhance competency levels enough to expect road safety benefits. Also, it is unlikely that these skills can be easily and safely acquired in real traffic because of the absence of consistent feedback, the rarity of high-risk events, and the severity of the consequences of incorrect decisions evidence-based RSE programmes may contribute to the acquisition of these skills, but require rigorous testing with respect to determinants of unsafe actions, training methods, and stages in the acquisition of skills that take into account the cognitive 
and social development of young adolescents (Bartholomew et al., 2006; Dreyfus and Dreyfus, 1980). Most likely, such programme development will show that just a half-day training will never be sufficient to ensure mastery of all possible scenarios in real traffic. More is therefore to be expected from extending the learning process so that it is not limited only to school-based programmes (Speelman and Kirsner, 2005; Twisk and Kuiken, 2006). This goal could be achieved by including additional support from computer-based tailored and interactive programmes that provide consistent feedback on performance and guide students through the different stages of the learning process (see Vlakveld, 2011 for an overview of mechanismes of simulation in training hazard perception skills), and by caretakers providing supervised training in real traffic. Simulation has been shown to be effective in hazard perception training of young drivers (Vlakveld et al., 2011), while supervised driving has been shown to improve road safety of novice drivers in the USA (Shope, 2007; Vanlaar et al., 2009) and the European Union (Twisk and Stacey, 2007).

One aspect that needs further exploration as part of the development of interventions is the possible role of cognitive immaturity, as this may affect what can be achieved by training. Recent studies on adolescent brain development show that some executive functions that are essential for safe traffic behaviour may be affected by structural changes in the prefrontal cortex (Blakemore and Choudhury, 2006, p. 307; Giedd, 2008). This development, however, does not fully limit the potential effects of RSE programmes, as these structural changes are also found to enhance the brain's capacity for acquiring new skills (Johnson et al., 2010; Keating and Halpern-Felsher, 2008), to increase the brain's sensitivity for experiential input (Blakemore and Choudhury, 2006, p. 307), and to direct attention and motivation depending on the social context (e.g., peer appraisal) (Crone and Dahl, 2012). Further exploration of the learning capacities of young adolescents may help in developing intervention programmes that are able to strike a balance between risk exposure and experiential learning, and that yield robust traffic skills that are not affected by interfering factors typical of young adolescents (Dahl, 2004), such as distractions, impulsivity, sensation-seeking, peer pressure, and absentmindedness.

\section{Acknowledgement}

The KPVV, TLN, and the Frysian Organisation of lorry drivers facilitated this study.

\section{References}

Anderson, J.R. (1982). The acquisition of cognitive skill. Psychological review 89 (4), 396-406.

Barnett, S.M., Ceci, S.J. (2002). When and where do we apply what we learn? A taxonomy for far transfer. Psychological Bulletin 128 (4), 612-637.

Bartholomew, L.K., Parcel, G.S., Kok, G., Gottlieb, N.H. (2006). Intervention Mapping: Designing Theory- and Evidence-Based Health Promotion Programs, 2nd ed. John Wiley \& Sons, Inc., San Fransisco. 
Blakemore, S.J., Choudhury, S. (2006). Development of the adolescent brain: implications for executive function and social cognition. Journal of Child Psychology and Psychiatry 47 (3-4), 296312.

Cook, T.D., Campbell, D.T. (1979). Quasi-Experimentation: Design and Analysis for Field Settings. Rand McNally, Chicago, IL.

Crone, E.A., Dahl, R.E. (2012). Understanding adolescence as a period of social- affective engagement and goal flexibility. Nature Reviews Neuroscience 13 (9), 636-650.

Dahl, R.E. (2004). Adolescent brain development: a period of vulnerabilities and opportunities. Keynote address. Annals of the New York Academy of Sciences 1021, 1-22.

Dorsselaer, S., van Zeijl, E., Eeckhout, S., van den Bogt, T., ter Vollebergh, W. (2007). HBSC 2005 Gezondheid en welzijn van jongeren in Nederland. Trimbos Instituut, Utrecht.

Dragutinovic, N., Twisk, D.A.M. (2006). The Effectiveness of Road Safety Education. A Literature Review R-2006-6. SWOV Institute for Road Safety Research, Leidschendam.

Dreyfus, S.E., Dreyfus, H.L.F. (1980). A Five-Stage Model of the Mental Activities Involved in Directed Skill Acquisition. Storming Media, Washington, DC (Retrieved 13.06.10).

Endsley, M.R. (1995). Toward a theory of situation awareness in dynamic systems. Human Factors 37 (1), 32-64.

Ericsson, K.A. (2005). Recent advances in expertise research: a commentary on the contributions to the special issue. Applied Cognitive Psychology 19 (2), 233-241.

Ezinga, M.A.J., Weerman, F.M., Westenberg, P.M., Bijleveld, C.C.J.H. (2008). Early adolescence and delinquency: levels of psychosocial development and self-control as an explanation of misbehaviour and delinquency. Psychology, Crime and Law 14 (4), 339-356.

Field, A. (2009). Discovering Statistics using SPSS, 3rd ed. Sage Publications, Ltd., London, UK.

Fuller, R. (2008). Driver training and assessment: implications of the task-difficulty homeostasis model. In: Dorn, L. (Ed.), Driver Behaviour and Training, vol. 3. Ashgate Publishing Limited, Aldershot.

Gardner, M., Steinberg, L. (2005). Peer influence on risk taking, risk preference, and risky decision making in adolescence and adulthood: an experimental study. Developmental Psychology 41 (4), 625-635.

Giedd, J.N. (2008). The teen brain: insights from neuroimaging. Journal of Adolescent Health 42 (4), 335-343.

Hauer, E. (2008). How many accidents are needed to show a difference? Accident Analysis and Prevention 40 (4), 1634-1635.

Johnson, S.B., Sudhinaraset, M., Blum, R. (2010). Neuromaturation and adolescent risk taking: why development is not determinism. Journal of Adolescent Research 25 (1), 4-23.

Jones, B. (2009). Split-plot designs: what, why, and how. Journal of quality technology 41 (4). 
Junger, M., Mesman, J., Meeus, W. (2003). Psychosociale problemen bij adolescenten, prevalentie risicofactoren en preventie. Van Gorcum, Assen.

Keating, D.P. (2007). Understanding adolescent development: implications for driving safety. Journal of Safety Research 38 (2), 147-157.

Keating, D.P., Halpern-Felsher, B.L. (2008). Adolescent drivers: a developmental perspective on risk, proficiency, and safety. American Journal of Preventive Medicine 35 (3 (Suppl. 1)), S272-S277.

Kumpula, H., Paavola, M. (2008). Injuries and Risk-taking Among Young People in Europe - The European Situation Analysis EU-Project AdRisk. KTL (National Public Health Institute), Helsinki.

Reyna, V.F., Farley, F. (2006). Risk and rationality in adolescent decision making: implications for theory, practice and public policy. Psychological Science in the Public Interest, A Supplement to Psychological Science 7 (1), 1-44.

Reyna, V.F., Rivers, S.E. (2008). Current theories of risk and rational decision making. Developmental Review 28 (1), 1-11.

Schoon, C.C., Doumen, M.J.A., de Bruin, D. (2008). De toedracht van dode hoekongevallen en maatregelen voor de korte en lange termijn: Een ongevallenanalyse over de jaren 1997-2007, verkeersobservaties en enquêtes onder fietsers en vrachtautochauffeurs, R-2008-11A. Institute for Road Safety Research, SWOV, Leidschendam.

Shope, J.T. (2007). Graduated driver licensing: review of evaluation results since 2002. Journal of Safety Research 38 (2), 165-175.

Shriffrin, R.M., Schneider, W. (1977). Controlled and automatic information processing. II. Perceptual learning, automatic attending and a general theory. Psychological Review 84 (127), 127-190.

Speelman, C.P., Kirsner, K. (2005). Chapter 2. Skill acquisition: history, questions, and theories. Beyond the Learning Curve, vol. 1. Oxford Scholarship Online Monographs, Oxford27-67.

Steinberg, L. (2008). A social neuroscience perspective on adolescent risk-taking. Developmental Review 28 (1), 78-106.

SUPREME (2007). SUPREME: Summary and Publication of Best Practices in Road Safety in the Member States: Thematic Report Education and Campaigns. Kuratorium für Verkehrssicherheit (KFV), Vienna.

Twisk, D., Kuiken, M.J. (2006). Education. In: Wegman, F.C.M., Aarts, L. (Eds.), Advancing Sustainable Safety. SWOV Institute for Road Safety Research, Leidschendam. Twisk, D.A.M., Stacey, C., 2007. Trends in young driver risk and countermeasures in European countries. Journal of Safety Research $38(2), 245-257$.

Vanlaar, W., Mayhew, D., Marcoux, K., Wets, G., Brijs, T., Shope, J. (2009). An evaluation of graduated driver licensing programs in North America using a meta-analytic approach. Accident Analysis and Prevention 41 (5), 1104-1111. 
Vlakveld, W., Romoser, M.R.E., Mehranian, H., Diete, F., Pollatsek, A.P., Fisher, D.L. (2011). Does the experience of crashes and near crashes in a simulator-based training program enhance novice driver's visual search for latent hazards? Transportation Research Board (2265), 154-160.

Vlakveld, W.P. (2011). Hazard anticipation of young novice drivers; assessing and enhancing the capabilities of young novice drivers to anticipate latent hazards in road and traffic situations. Dissertation Thesis, SWOV-Dissertatiereeks. Stichting Wetenschappelijk Onderzoek Verkeersveiligheid SWOV, Leidschendam.

Williams, A.F. (2007). Public Information and Education in the Promotion of Highway Safety. Transport Reserach Board (TRB) of the National Academy of Sciences, Washington. 